\title{
Recovery of a Vietnamese Child from Impaired Fasting Glucose and Hyperinsulinemia After one Year of Implementation of an Appropriate Diet Plan: A Case Report
}

\author{
Thi Huyen La ${ }^{1,2}$ and Thi Nhu Ngoc Van ${ }^{3 *}$ \\ ${ }^{1}$ Institute of Biotechnology, Vietnam Academy of Science and Technology, Hanoi, Vietnam \\ ${ }^{2}$ Graduate University of Sciences and Technology, Vietnam Academy of Science and Technology, Hanoi, Vietnam \\ ${ }^{3}$ CNRS, SYS2DIAG-ALCEDIAG, Cap delta, 1682 rue de la Valsière, Montpellier, France
}

*Corresponding author: Thi Nhu Ngoc Van, CNRS, SYS2DIAG, UMR9005, Cap delta, 1682 rue de la Valsière, Montpellier, F-34184, France

ARTICLE INFO

Received: 幽 June 15, 2021

Published: 慧 July 15, 2021

Citation: Thi Huyen La, Thi Nhu Ngoc Van. Recovery of a Vietnamese Child from Impaired Fasting Glucose and Hyperinsulinemia After One Year of Implementation of An Appropriate Diet Plan: A Case Report. Biomed J Sci \& Tech Res 37(2)-2021. BJSTR. MS.ID.005969.

Keywords: Type 2 Diabetes Mellitus; Hyperinsulinemia; Alopecia Areata; High Fat Low Carb Diet; Anti-Inflammatory Diet; Children; Vietnam

Abbreviations: T2D: Type 2 Diabetes; BMI: Body Mass Index; IFG: Impaired Fasting Glucose; NLR: Neutrophils Lymphocytes Ratio

\section{ABSTRACT}

Background: Increasing type 2 diabetes mellitus (T2D) in children and adolescents has bypassed the living standard barrier among countries to become a global epidemics. The diagnosis of T2D often focuses on overweight or obese individuals which leaves behind the normal Body Mass Index (BMI) ones whose late diagnosis causes grave complications and consequences. Changing diet and lifestyle are affective means for the management of the disease.

Method: A 9-year-old normal weight Vietnamese male with a BMI of $23.3 \mathrm{~kg} / \mathrm{m} 2$ was diagnosed with impaired fasting glucose (IFG) and hyperinsulinemia a in December 2019 after intensive treatments for severe hair loss progression (Alopecia areata). The patient was under both topical and oral cortisol (4mg of Methylprednisolone and $0.1 \%$ Mometasone furoate, daily), fasting blood glucose was $6.6 \mathrm{mmol} / \mathrm{L}, \mathrm{HbA} 1 \mathrm{C}$ was $5.1 \%$, fasting insulin was $123.048 \mu \mathrm{U} / \mathrm{mL}, \mathrm{C}$-peptide was $4.7 \mathrm{nmol} / \mathrm{L}$ and a complete hair loss. His white blood count showed an increase in \% Lymphocytes associated with a decrease in: \% Neutrophils, number of Eosinophils and number of Basophils. He was born $4.1 \mathrm{~kg}$ and his mother did not have gestational diabetes. He adopted an anti-inflammatory diet protocol for the first 6 months which was then extended to high fat low carb diet.

Result: After about one year of changing his diet, from May 2020 to April 2021, the patient was off all his medications, his blood test was back to normal (glucose, HbA1C, insulin and C-peptide are $4.22 \mathrm{mmol} / \mathrm{L}, 4.94 \%, 3.9 \mu \mathrm{U} / \mathrm{mL}, 0.72 \mathrm{nmol} / \mathrm{L}$ respectively) and his complete blood count has completely recovered. However, there have been no signs of recovery for his hair loss.

Conclusion: The adoption of an appropriate diet is an effective tool for the prevention of T2D progression as well as the management of the disease. Thanks to changes in his diet, the patient has recovered from not only IFG and hyperinsulinemia but also the severe inflammation which, if left advanced, could have led to other complications including the development of polygranular autoimmune disease. Routine screening and early diagnosis of T2D, impaired fasting glucose and hyperinsulinemia are recommended to help patients to avoid serious consequences from the disease complications. Children and adults with normal BMI should be paid as much attention as to those whose BMI is high. 


\section{Introduction}

Global increase in T2D in children and aldolesents has raised a serious concern on the health condition of the future generation. Combination of multiple risk factors such as genetics, the mother's gestational diabetes, poor diet and lifestyle are considered as the cause of this rise (Castorani, et al. [1]). While there are no possible actions can be done to change the genetics of the person, adopting an appropriate personalized diet and lifestyle represents the sole option for the prevention of the disease pathogenesis and management. High fat low carb diet has demonstrated health benefits in restoring metabolic syndroms and other diseases (Walton, et al. [2]) (Dowis, et al. [3]). Recent data shows a significant increase in T2D mellitus as well as in prevalence of non-diagnosed T2D in children worldwide (Spurr, et al. [4]). In Vietnam, it was reported in a recently published study that the prevalence of T2D in children from 11-14 years old is lower than in most countries and the impaired fasting glucose prevalence is up to 6.5\% (Phan, et al. [5]). T2D mellitus in children is often diagnosed only when grave complications have already occurred because of the poor risk management and the lack of surveillance programs and tools.
Consequently, pediatric patients risk being put on medicaments including insulin injection at a very young age. We report here a case of a 9-year-old Vietnamese male diagnosed with IFG and hyperinsulinemia in December 2019 following cortisol treatment (from August 2018) for severe hair loss (Alopecia areata). One year after changing his diet, the patient has restored his IFG, insulin, complete blood count and re-started to grow taller after more than one year staying at the same height.

\section{Case Report}

A 9-year-old male presented at the hospital in August 2018 with alopecia areata symptoms. He was put on a treatment of $4 \mathrm{mg}$ of Methylprednisolone and $0.1 \%$ Mometasone furoate, daily. His severe hair loss was advancing rapidly to complete hair loss within one year (Figures 1A \& 1B). The patient was with a normal BMI of $23.3 \mathrm{~kg} / \mathrm{m} 2$ and none of the blood tests for diagnosis of T2D was performed upon his first visit to the hospital. On another visit to the hospital on December 2019, he gained $5 \mathrm{~kg}$ and was diagnosed with T2D with fasting glucose of $6.6 \mathrm{mmol} / \mathrm{L}, \mathrm{HbA} 1 \mathrm{C}$ of $5.1 \%$, a very high fasting insulin of $123.048 \mu \mathrm{U} / \mathrm{mL}$ and C-peptide of $4.7 \mathrm{nmol} / \mathrm{L}$. He was then put on metformin while continuing the cortisol treatment.

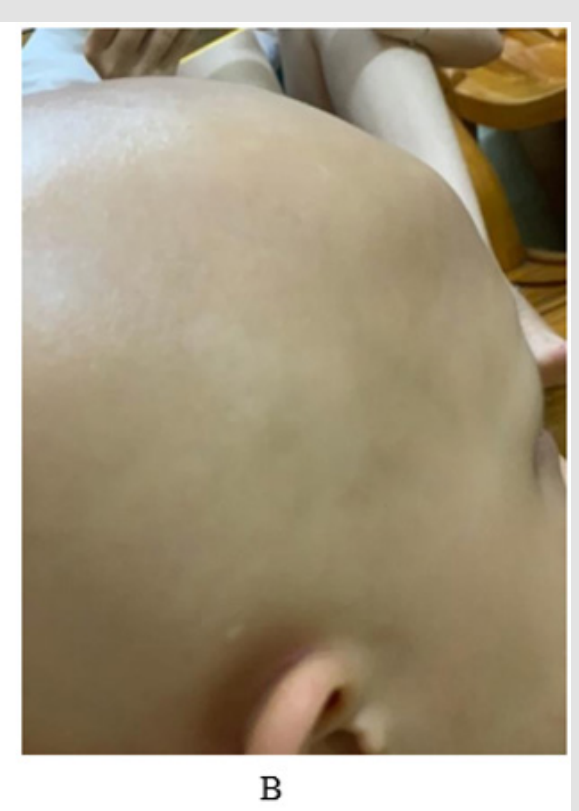

Figure 1: Hair loss progression of the patient

A) Photo taken at the beginning of the hair loss in August 2018.

B) photo taken in May 2020.

\section{Results}

His mother was seeking help outside of the conventional medical approach, reaching to her research scientist friends in Vietnam and oversea. As provided by the mother, the patient was born lightly overweight ( $4.1 \mathrm{~kg}$ ) and has itchy skin at birth. He got his first dent only at one year old and his nail grew slowly and has remained weak. No intensive treatment of neither antibiotic or anti-inflammatory drug was used prior to the appearance of alopecia areata. Eczema had appeared shortly before the hair loss. The patient's blood test showed an IFG associated with hyperinsulinemia (Table 1, Dec 2019) and a severe inflammation in the white blood count panel (Table 2, Dec 2019 and Jan 2020). A reduction in Neutrophils and an increase in Lymphocyte count reflects a decrease in Neutrophils Lymphocytes Ratio (NLR) which 
is implicated in prognosis of systemic inflammation, infection and even cancer survivor rate (Bowen, et al. [6,7]). Since the naissance, the patient had had a conventional Vietnamese diet with high carb low fat meals consisting mainly of rice and vegetables. A part from 3 main meals, he had small snacks from 3 to 4 times a day which are formulated milk, soda, tropical fruits, potato chips, sweets and cookies. He pooped only every 3 days. From May 2020 we suggested his family to adopt an anti-inflammatory diet to first reduce the severe inflammation condition. The diet aims to eliminate the intake of all potential inflammatory elements such as lectin and omega 6.

In summary, the first diet plan excluded: All seed oils, all legumes, night shade vegetables, egg, coconut, nuts, rice, rice noodle, sticky rice, wheat flour, bread and all refined sugar food and drinks including soft drink, juices, sweet, cookies, ice cream, etc. Glutamate which is casually used in cooking in Vietnam as well as all prepared sauces which often contain high amounts of sugar were both removed from the diet. Soy and dairy products were also eliminated. Alternatively, all cooking and meal preparation used a generous amount of olive oil, butter and animal fat. Table salt was replaced by sea and Himalaya salt. Fruits were limited to avocado, berries and cucumber. Whole food consumption were mainly cruciferous and green leafy vegetables, aromatic herbs, grass fed meat and/or wild caught small size fishes. Bone broth and lemon juice were consumed daily. Red meat, organ meat, shellfish, fermented vegetables and prebiotic drinks (kombucha) were added regularly to his diet. He started with three meals per day with no snacks in between and eventually reduced to 2 meals per day for 3 or 4 day per week. By August 2020 (Table 1), his blood test showed a significant reduction in fasting insulin level (from above 123 to 7.4 $\mu \mathrm{U} / \mathrm{mL}$ ) while he was off of all his medications. He restored his blood Fe to normal level and slightly improved his white blood count panel (Table 2) showing promising recovery from both T2D and inflammation. Pooping frequency was also gradually improved, from once every three days to every $18-24 \mathrm{~h}$. The patient has stayed active and full of energy. He started regain height (from $139 \mathrm{~cm}$ to $141 \mathrm{~cm}$ ).

Table 1: Blood test results over the time following his diet changes.

\begin{tabular}{|c|c|c|c|c|c|c|c|}
\hline \multirow{2}{*}{ Blood test } & \multicolumn{5}{|c|}{ Date } & \multirow{2}{*}{ Referent Value } & \multirow{2}{*}{ Unit } \\
\hline & Dec 2019 & Jun 2020 & Aug 2020 & Dec 2020 & Apr 2021 & & \\
\hline Glucose & 6.6 & 5.17 & & 5.3 & 4.22 & $3.9-6.4$ & $\mathrm{mmol} / \mathrm{L}$ \\
\hline $\mathrm{HbA1C}$ & 5.1 & 5.4 & 5.89 & 5 & 4.94 & $3.4-6.5$ & $\%$ \\
\hline Insulin & 123.048 & & 7.4 & 9.34 & 3.9 & $2.7-10.4$ & $\mu \mathrm{U} / \mathrm{mL}$ \\
\hline C-peptide & 4.7 & & & & 0.72 & $0.37-1.47$ & $\mathrm{nmol} / \mathrm{L}$ \\
\hline T3 & & 2.28 & & 1.45 & 1.67 & $1.3-3.1$ & $\mathrm{nmol} / \mathrm{L}$ \\
\hline FT4 & 18.39 & 20 & & 11.65 & 11.85 & $9.0-24.0$ & $\mathrm{pmol} / \mathrm{L}$ \\
\hline TSH & 1.86 & 2.57 & & 4 & 2.81 & $0.35-5.5$ & $\mathrm{uU} / \mathrm{mL}$ \\
\hline $\mathrm{Fe}$ & & 10.44 & 12.7 & & & $12.5-32.2$ & umol/L \\
\hline
\end{tabular}

Table 2: Complete blood count results over the time following his diet changes.

\begin{tabular}{|c|c|c|c|c|c|c|c|}
\hline \multirow{2}{*}{ Blood count } & \multicolumn{5}{|c|}{ Date } & \multirow{2}{*}{ Referent value } & \multirow{2}{*}{ Unit } \\
\hline & Dec 2019 & Jan 2020 & Jun 2020 & Aug 2020 & Dec 2020 & & \\
\hline $\mathrm{RBC}$ & 4.57 & 4.82 & 4.87 & 5.37 & 5.14 & $4.2-5.4$ & $\mathrm{~T} / \mathrm{L}$ \\
\hline HGB & 132 & 134 & 142 & 149 & 147 & $130.0-160.0$ & $\mathrm{~g} / \mathrm{L}$ \\
\hline HCT & 0.39 & 0.405 & 0.43 & 0.43 & 0.44 & $0.42-0.49$ & $\mathrm{~L} / \mathrm{L}$ \\
\hline MCV & 84.4 & 84.1 & 88.1 & 80.9 & 85.4 & $80.0-100.0$ & $\mathrm{fL}$ \\
\hline $\mathrm{MCH}$ & 28.8 & 27.9 & 29.1 & 27.8 & 29 & $27.0-31.2$ & pg \\
\hline $\mathrm{MCHC}$ & 341 & 332 & 330 & 344 & 335 & $315.0-363.0$ & $\mathrm{~g} / \mathrm{L}$ \\
\hline RDW & 13.1 & 12.6 & 13.2 & 14.2 & 11.9 & $10.0-15.0$ & $\%$ \\
\hline PLT & 373 & 340 & 312 & 238 & 355 & $150.0-400.0$ & $\mathrm{~g} / \mathrm{L}$ \\
\hline MPV & 7 & 7.5 & 7.5 & 9.5 & 9.5 & $5.0-20.0$ & $\mathrm{fL}$ \\
\hline РCT & & 0.2397 & 0.23 & 0.226 & & & \\
\hline PDW & & 18.98 & 15.9 & 10.3 & & & \\
\hline WBC & 5.4 & 5.82 & 5.3 & 4.53 & 8.33 & $4.0-10.0$ & $\mathrm{~g} / \mathrm{L}$ \\
\hline$\% \mathrm{NEU}$ & 51.7 & 46.8 & 38.91 & 44 & 60.3 & $60.0-70.0$ & $\%$ \\
\hline$\%$ EO & 2.3 & 2.21 & 2.49 & 2.3 & 1.3 & $0.0-8.0$ & $\%$ \\
\hline
\end{tabular}




\begin{tabular}{|c|c|c|c|c|c|c|c|}
\hline \% BASO & 0.8 & 1.26 & 0.87 & 0.2 & 0.5 & $0.0-1.0$ & $\%$ \\
\hline \% MONO & 8 & 7.76 & 8.22 & 5.8 & 7.6 & $0.0-8.0$ & $\%$ \\
\hline \% LYMPH & 37.2 & 42 & 49.51 & 47.7 & 30.1 & $25.0-35.0$ & $\%$ \\
\hline NEU & 2.8 & 2.73 & 1.96 & 1.99 & 5 & $2.8-5.5$ & $\mathrm{~g} / \mathrm{L}$ \\
\hline EO & 0.1 & 0.129 & 0.13 & 0.01 & 0.11 & $0.0-0.8$ & $\mathrm{~g} / \mathrm{L}$ \\
\hline BASO & 0 & 0.074 & 0.04 & 0.1 & 0.04 & $0.01-0.12$ & $\mathrm{~g} / \mathrm{L}$ \\
\hline MONO & 0.4 & 0.452 & 0.41 & 0.26 & 0.63 & $0.0-0.8$ & $\mathrm{~g} / \mathrm{L}$ \\
\hline LYMPH & 2 & 2.44 & 2.49 & 2.17 & 2.51 & $1.0-4.5$ & $\mathrm{~g} / \mathrm{L}$ \\
\hline
\end{tabular}

In Dec 2020, his blood test showed an improvement in HbA1C (Table 1) and more importantly a significant improvement in white blood count (Table 2) and the NLR (Table 3) which shows no more inflammation. Nevertheless, his thyroid panel shows a tendency of hypothyroidism with the TSH closed to the upper limit (Table 2). From Dec 2020, the diet protocol was extended to a classical low carb high fat moderate protein diet. We re-introduced, with a moderate quantity of certain fruits and vegetables such as tomato without the skin and seed, pomelo, papaya and pomegranate; pumpkin seed and almond; heavy cream and high fat chesses; coconut milk and egg yolk. He continued to skip his breakfast 3 to 4 times per week with no snacks in between. He was supplemented with vitamin D3, vitamin $\mathrm{K} 2$, nutritional yeast for group B vitamin, zin, selenium, sea kelp, potassium citrate and magnesium citrate. In April 2021, his blood test showed that he is no longer IFG with a normal level of fasting insulin and C-peptide. He has recovered from the risk of hypothyroidism (Table 1) and continue to grow taller. All his antibody tests (ANA, ICA, GDA and TPO) for autoimmune disorders were negative (Data is not shown). His hair lost unfortunately has not shown any recovery.

Table 3: Neutrophil Lymphocyte Ratio results over the time following his diet changes.

\begin{tabular}{|c|c|c|c|c|c|c|c|}
\hline \multirow{2}{*}{ Blood count } & \multicolumn{5}{|c|}{ Date } & \multirow{2}{*}{ Referent value } & \multirow{2}{*}{ Unit } \\
\hline & Dec 2019 & Jan 2020 & Jun 2020 & Aug 2020 & Dec 2020 & & \\
\hline WBC & 5.4 & 5.82 & 5.3 & 4.53 & 8.33 & $4.0-10.0$ & $\mathrm{~g} / \mathrm{L}$ \\
\hline NEU & 2.8 & 2.73 & 1.96 & 1.99 & 5 & $2.8-5.5$ & $\mathrm{~g} / \mathrm{L}$ \\
\hline LYMPH & 2 & 2.44 & 2.49 & 2.17 & 2.51 & $1.0-4.5$ & $\mathrm{~g} / \mathrm{L}$ \\
\hline NLR & 1.4 & 1.12 & 0.79 & 0.92 & 1.99 & & \\
\hline
\end{tabular}

\section{Discussion}

The rise of T2D mellitus in children in developing countries like Vietnam is regarded to be caused by the westernization of their conventional diet or the combination of both. Impact of the introduction of a number of snacks and high sugar beverages to the routine consumption upon three conventional meals filled with rice and starchy vegetables must be taken into account for T2D epidemics in Vietnam and Asia, especially in children of young age. Prior to the arrival of alopecia areata, the patient did not show any symptoms of T2D or autoimmune disorders. He was not overweight and didn't endured any intensive treatment of antibiotic or/and anti-inflammation prior to the severe and rapid hair loss. As there were no blood tests for fasting glucose and insulin before starting the cortisol treatment, we cannot know if the treatment had contributed to graver his IFG and hyperinsulinemia condition. As alopecia areata is often associated with insulin-dependent diabetes (Wang, et al. [8]) and taking into account his previous diet, it is likely that he possessed a pre-existing hyperinsulinemia condition long before the appearance of the severe hair loss.
Routine screening for IFG and hyperinsulinemia in children is highly recommended for T2D prevention which will help to avoid such serious consequences to the physical, physiological and psychological conditions and the development of the child. Treatment of T2D mellitus in children by medication can be avoided by better management of diet and life style. However, it is challenging as successful employment of such changes in diet and lifestyle requires a strong willingness and collaboration of both the child and his family. Notwithstanding the social influences on the implementation of the diet as consumption of refined sugary foods, snacks and drinks are widely used and accepted at all social events. Despite all these difficulties and social inconveniences, the patient and his family have made a huge step forward, helping the child to recover from his diseases and to continue his growing curve right before entering puberty. His recovery encourages many others to take actions as showing that adopting an appropriate diet may not be an easy option but is the one that works.

\section{Conclusion}

Implementation of an anti-inflammatory diet followed by an extension to low carb high fat diet has rescued the 9-year-old 
child, now is 10 years old, not only from the development of T2D mellitus but also the severe inflammation. Routine screening for IFG and hyperinsulinemia in children is highly recommended for the prevention of the $\mathrm{T} 2 \mathrm{D}$ and therefore reduction of serious complications and consequences.

\section{Acknowledgement}

We thank Mrs Pham Thi Huong and her family for their effort during the implementation of the diet and for providing necessary information for this report. We thank the patient Cao Duy Hung for his collaboration and willingness to bypass social inconveniences to implement changes in his diet. All blood tests were self-funded by the family of the patient. We thank the Vietnam Academy of Science and Technology, Hanoi, Vietnam for funding the fee of submission of the report.

\section{Author Contributions}

Dr. Thi Nhu Ngoc Van consulted the family for implementation of the diet plans, followed up the improvement of the results and wrote the manuscript. Dr. Thi Huyen La consulted the family to seek help from the non-conventional medical approaches and collected and analysis the data. Both authors revised the manuscript.

ISSN: 2574-1241

DOI: 10.26717/BJSTR.2021.37.005969

Thi Nhu Ngoc Van. Biomed J Sci \& Tech Res

(C) (P) This work is licensed under Creative

Submission Link: https://biomedres.us/submit-manuscript.php

\section{References}

1. Castorani V, Polidori N, Giannini C, Blasetti A, Chiarelli F (2020) Insulin resistance and type 2 diabetes in children. Ann Pediatr Endocrinol Metab 25: 217-226.

2. Walton CM, Perry K, Hart RH, Berry SL, Bikman BT (2019) Improvement in Glycemic and Lipid Profiles in Type 2 Diabetics with a 90-Day Ketogenic Diet. J Diabetes Res 2019: 8681959.

3. Dowis K, Banga S (2021) The Potential Health Benefits of the Ketogenic Diet: A Narrative Review. Nutrients 13(5): 1654.

4. Spurr S, Bally J, Hill P, Gray K, Newman P, et al. (2020) Exploring the Prevalence of Undiagnosed Prediabetes, Type 2 Diabetes Mellitus, and Risk Factors in Adolescents: A Systematic Review. J Pediatr Nurs 50: 94 104.

5. Phan DH, Do VV, Khuong LQ, Nguyen HT, Minh HV (2020) Prevalence of Diabetes and Prediabetes among Children Aged 11-14 Years Old in Vietnam. J Diabetes Res 2020: 1-8.

6. Bowen RC, Little NAB, Harmer JR, Ma J, Mirabelli LG, et al. (2017) Neutrophil-to-lymphocyte ratio as prognostic indicator in gastrointestinal cancers: A systematic review and meta-analysis. Oncotarget 8(19): 32171-32189.

7. Song M, Graubard BI, Rabkin CS, Engels EA (2021) Neutrophil-tolymphocyte ratio and mortality in the United States general population. Sci Rep 11: 464.

8. Wang SJ, Shohat T, Vadheim C, Shellow W, Edwards J, et al. (1994) Increased risk for type I (insulin-dependent) diabetes in relatives of patients with alopecia areata (AA). Am J Med Genet 51: 234-239.

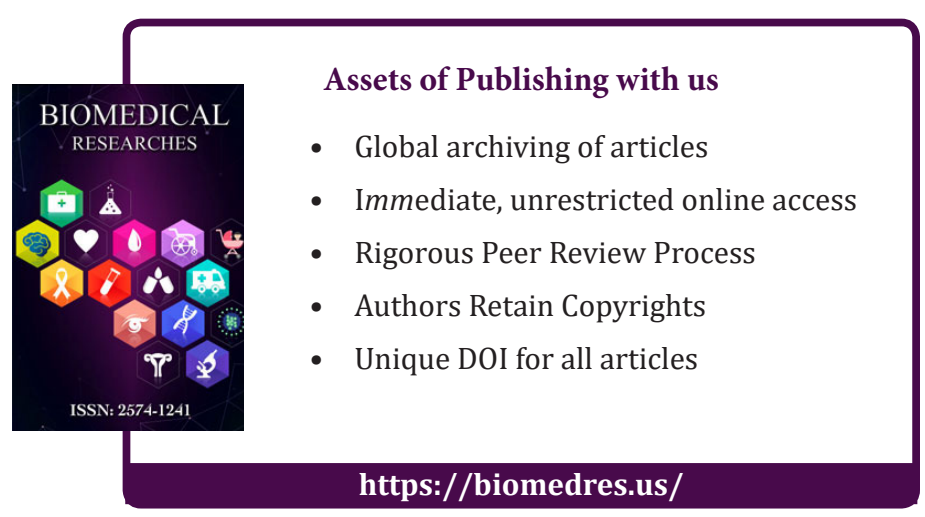

